\title{
A New Tool for Resistance Management: Baseline Toxicity, Ovicidal Activity, and Field Efficacy of the Novel Insecticide Tolfenpyrad on Colorado Potato Beetle, Leptinotarsa decemlineata
}

\author{
Adam F. Wimer ${ }^{*}$, Christopher R. Philips², Thomas P. Kuhar ${ }^{1}$, James C. Adams ${ }^{3}$, \\ Zsofia Szendrei ${ }^{4}$ \\ ${ }^{1}$ Department of Entomology, Virginia Polytechnic Institute and State University, Blacksburg, USA \\ ${ }^{2}$ Department of Entomology, North Central Research \& Outreach Center, University of Minnesota, \\ Grand Rapids, USA \\ ${ }^{3}$ Nichino America, Inc., Newark, USA \\ ${ }^{4}$ Department of Entomology, Michigan State University, East Lansing, USA \\ Email: awimer@vt.edu
}

Received 6 October 2015; accepted 26 October 2015; published 29 October 2015

Copyright @ 2015 by authors and Scientific Research Publishing Inc.

This work is licensed under the Creative Commons Attribution International License (CC BY). http://creativecommons.org/licenses/by/4.0/

(c) (i) Open Access

\section{Abstract}

Leptinotarsa decemlineata (Say) (Coleoptera: Chrysomelidae) is one of the most important insect pests of potato (Solanum tuberosum L.). Because of the high value of potato crops, most growers approach management in a similar manner. Chemical control of arthropod pests in potato is the standard pest management practice, and will likely continue to be in the foreseeable future. This heavy reliance on chemical control has led to high levels of insecticide resistance. Strategies that rotate chemistries are critical in order to maintain insecticide efficacy, highlighting the immediate need to evaluate novel chemistries to continue to manage this pest successfully. Working with different populations of $L$. decemlineata, field and lab experiments were conducted to evaluate the baseline toxicity, ovicidal activity, and field efficacy of the novel insecticide tolfenpyrad to $L$. decemlineata. Lab assays revealed that tolfenpyrad was toxic to both larvae and adults, and that $L$. decemlineata treated egg masses had a $0 \%$ hatch rate. Potato field plots treated with tolfenpyrad had significantly fewer larvae, less defoliation, and higher tuber yields. These data will provide accurate field rates for proper labeling, a baseline reference for tracking changes in $\mathbf{L}$. decemlineata susceptibility, as well as provide a novel chemistry to aid in resistance management programs.

\footnotetext{
${ }^{*}$ Corresponding author.
} 


\title{
Keywords
}

\author{
Toxicity, Tolfenpyrad, Colorado Potato Beetle, Leptinotarsa decemlineata, $\mathrm{LC}_{50}$, Resistance \\ Management
}

\section{Introduction}

Leptinotarsa decemlineata (Say) (Coleoptera: Chrysomelidae) is one of the most important insect pests of potato (Solanum tuberosum L.). Native to Mexico, L. decemlineata likely migrated into the Great Plains of North America in the 1800s [1] [2] and quickly became the most destructive pest of cultivated potato throughout the US and Canada [3]. Uncontrolled populations can completely defoliate potato fields, which can lead to a total loss of tuber production [3] [4]. In Virginia, minimum yield losses of 50\% typically occur in potato if $L$. decemlineata is not managed [5]-[7].

Leptinotarsa decemlineata is a specialist feeding only on solanaceous crops. These crops have elevated concentrations of toxic glycoalkoloids in their foliage, thus these insects have developed effective means to detoxify and excrete these toxins in their diet [8]-[10]. This ability to detoxify these plant toxins also facilitates their ability to develop resistance. In addition, the relatively high fecundity of $L$. decemlineata results in large populations in a short period of time [3].

In addition to specializing in circumventing these toxins, $L$. decemlineata also face a tremendous selection pressure for resistance. Most solanaceous crops, including potato, eggplant, and tomato, are considered high value crops. For this reason, most of these crops are intensively managed with conventional insecticides. Feeding almost exclusively on intensively managed crops drastically increase the selection pressure for resistance by reducing the amount of refuge that is available to L. decemlineata [9]-[11]. This is evidenced by L. decemlineata seemingly innate ability to develop resistance to the insecticides used for control. Leptinotarsa decemlineata has a propensity for resistance development with some level of resistance being documented for 55 different active ingredients in nearly all insecticide groups [10] [12] [13]. While resistance varies between populations and regions, the homogeneity in management of potato increases the risk of resistance [12] [14]-[16].

Chemical control of arthropod pests in potato has been the standard pest management practice for more than a century [17], and will likely continue to be in the foreseeable future [2]. Since the 1990s, potato growers have relied on neonicotinoid insecticides as the foundation of pest management [12]. This overreliance on a single class of insecticide has led to a steady decrease in efficacy, and control [10] [18] [19]. Overreliance, combined with increased regulatory pressures to reduce the use of neonicotinoid insecticides may eliminate these chemicals as a management option in the future. Moreover, from a resistance management perspective, strategies that rotate chemistries are critical in order to maintain insecticide efficacy. This highlights the immediate need to evaluate novel chemistries to continue to manage this pest successfully. Tolfenpyrad is a broad spectrum insecticide that was discovered by the Mitsubishi Chemical Corporation (now the Nihon Nohyaku Co. Ltd.) in 1996, and was labeled in Japan for use on vegetables and ornamentals in 2002, and fruit trees in 2003 [20]. Tolfenpyrad, 4-chloro-3-ethyl-1-methyl- $N$-[4-( $p$-tolyloxy) benzyl]pyrazole-5-carboxamide, is a novel broad spectrum insecticide currently being developed by the Nihon Nohyaku Co. Ltd. Labeled by the US EPA for use on potato in states west of the Mississippi River in 2013, it has been classified by the Insecticide Resistance Action Committee (IRAC) in Group 21. Specifically, tolfenpyrad impedes cellular respiration by inhibiting complex I of the mitochondrial electron transport chain. Insect response from exposure to tolfenpyrad is rapid and includes termination of movement and feeding, lack of fecundity, and death. Tolfenpyrad has a positive mammalian toxicology profile with an acute oral toxicity of $386 \mathrm{mg} \mathrm{kg}^{-1}$, acute dermal toxicity of $2000 \mathrm{mg} \mathrm{kg}^{-1}$, and an acute inhalation toxicity of $2.21 \mathrm{mg} \cdot \mathrm{kg}^{-1}$. This novel insecticide has no reported cross resistance to other insecticides, which is highly attractive for use against $L$. decemlineata [21].

Herein, we report laboratory studies determining the ovicidal activity, baseline toxicity of tolfenpyrad to $L$. decemlineata larvae and adults, as well as field tests evaluating the efficacy of different rates on L. decemlineata larva and adults. These data will provide accurate field efficacy rates for tolfenpyrad for proper labeling of this new insecticide as well as a baseline reference for tracking changes in L. decemlineata susceptibility, so that early stages of resistance can be detected in time for mitigation, as well as provide a novel chemistry to aid in resistance management programs. 


\section{Materials and Methods}

\subsection{Insecticide}

All experiments were conducted with commercially formulated tolfenpyrad 15 EC (15\% ai.; 150 g ai/L) obtained from Nichino America, Inc at the beginning of each experimental year. All rates are based on manufactures suggested rate or the current product label.

\subsection{Leaf-Dip Bioassays}

Experiments were conducted from 2010 to 2012 at the Virginia Tech Eastern Shore Agricultural Research and Extension Center (ESAREC) in Painter, VA. Leptinotarsa decemlineata adults and larvae ( $2^{\text {nd }}$ and $3^{\text {rd }}$ instars $)$ were sight identified in the field and collected from insecticide-free potato plots at the ESAREC.

Leaf-dip bioassays were conducted separately on larvae $\left(2^{\text {nd }}-3^{\text {rd }}\right.$ instars $)$ and adult $L$. decemlineata. An initial (stock) rate of tolfenpyrad was calculated from a suggested field application rate of $230 \mathrm{~g}$ ai/ha. This was equivalent to a concentration of $4.57 \mathrm{~mL}$ product/liter $(=0.685 \mathrm{~g}$ ai $/ \mathrm{L})$. Five serial dilution concentrations $(6.85,0.685$, $0.0685,0.00685$, and $0.000685 \mathrm{~g}$ ai/L) plus a water control were evaluated in these experiments. Each concentration was replicated four times and each replication consisted of a single dipped potato leaf and ten larvae. Unblemished potato leaves were completely submerged in each treatment and allowed to air dry. Once dry, 10 larvae or 10 adults were placed in either a $9 \mathrm{~cm}$ or a $15 \mathrm{~cm}$ diameter Petri dish with each treated leaf, respectively. Adult $L$. decemlineata assays included two leaves per Petri dish. Mortality was assessed after 72 hours. Larvae and adults were considered dead or moribund if they did not respond to gentle probing or could not right themselves if turned upside down.

\subsection{Egg Mass Bioassays}

In 2012 and 2013, L. decemlineata egg masses from Virginia and Michigan were collected and exposed to either water or the high field rate of tolfenpyrad, $230 \mathrm{~g}$ ai/ha. Ten egg masses from each location for each treatment were tested. Egg masses were completely submerged in tolfenpyrad or in a non-treated water control. Once exposed, the egg masses were placed in $9 \mathrm{~cm}$ Petri dishes, maintained at room temperature, and observed for 3 to 5 days to determine the number of eggs from each egg mass that hatched. Egg masses from multiple populations were evaluated to include some lab-reared populations resistant to neonicotinoid insecticides (Table 1).

\subsection{Field Efficacy Experiments}

Experiments were conducted in 2010, 2011, and 2012 at the ESAREC, to evaluate the field efficacy of tolfenpyrad on L. decemlineata larvae. Potato seed pieces "Superior" were planted on 25 March, 13 April, and 21 March in 2010, 2011, and 2012, respectively. Potatoes were grown on Bojak sandy loam soils following standard commercial cultivation and production practices for eastern Virginia including: a seed spacing of $30 \mathrm{~cm}$ within a row and between row spacing of $0.9 \mathrm{~m}$; pre-plant herbicide applications (S-metalochlor and metribuzin at labeled rates), fertilizer application at first hilling cultivation, foliar spray applications of fungicides as needed for Late Blight control, and overhead sprinkler irrigation sparingly as needed during early summer drought periods. Each trial was set up in a randomized complete block design; in 2010 and 2011, each treatment was replicated four times and in 2012, each treatment was replicated six times. Individual plots consisted of two rows of

Table 1. Number of $L$. decemlineata egg masses that hatched after being exposed to tolfenpyrad (230 g·ai/ha) or a nontreated control (NTC) of water. Egg masses from Virginia were collected from a field population in Blacksburg, VA, in 2012. The remaining egg masses were from laboratory-reared colonies maintained in East Lansing MI, 2013.

\begin{tabular}{ccccccc}
\hline & \multicolumn{5}{c}{ Number of egg masses hatching/ten egg masses treated } \\
\hline Treatment & Evans $^{z}$ & Evans $^{z}$ & Hadley $^{y}$ & New York $^{z}$ & New Jersey $^{x}$ & Virginia $^{2}$ \\
\hline NTC & 10 & 10 & 10 & 10 & 10 & 10 \\
Tolfenpyrad & 0 & 0 & $0^{w}$ & 0 & 0 & 0 \\
\hline
\end{tabular}

${ }^{z}$ Laboratory populations resistant to imidacloprid. ${ }^{y}$ Laboratory population resistant to thiamethoxam. ${ }^{x}$ Laboratory susceptible population. ${ }^{w} \mathrm{~A}$ single egg hatched out of the ten egg masses tested. 
potato. Three suggested rates of tolfenpyrad were evaluated 153, 186, and $230 \mathrm{~g}$ ai/ha. Two foliar applications of insecticides were applied one week apart upon the first observation of small larvae in the field. Applications of insecticides were made on 11 and 18 May, 20 and 27 May, and 12 and 21 May in 2010, 2011 and 2012, respectively. In 2010, to evaluate the potential synergistic effect of the pyrethroid $\beta$-cyfluthrin with tolfenpyrad a single treatment of the low rate of tolfenpyrad was mixed with $\beta$-cyfluthrin at a rate of $14 \mathrm{~g}$ ai/ha. All treatments were compared to a commercial standard, $\beta$-cyfluthrin ( $14 \mathrm{~g}$ ai/ha), as well as an untreated control. In all three years applications were applied using a $\mathrm{CO}_{2}$ powered backpack sprayer equipped with a four-nozzle boom with flat spray nozzles (TeeJet 110003 VS) spaced $50.8 \mathrm{~cm}$ apart at $2.721 \mathrm{~atm}$. Each treatment was evaluated by counting the number of $L$. decemlineata small and large larvae found on 10 arbitrarily chosen potato stems in each plot. Defoliation was measured as a percentage of all plants in each plot through visual estimation after larval feeding had ceased on 14 Jun, 10 Jun, and 6 Jun in 2010, 2011, and 2012, respectively. Yield was evaluated by mechanical harvest and tubers were graded by size according to US standards (Grade B, small A, large A, and Chef) [22]. Potato tubers were harvested on 1 July, 13 July, and 28 Jun in 2010, 2011, and 2012, respectively.

\subsection{Statistical Analysis}

Tolfenpyrad $\mathrm{LC}_{50}$ and 95\% confidence limits for small larvae and adult $L$. decemlineata using leaf-dip bioassays analyzed with standard Probit analysis in GraphPad Prism, version 5 [23]. Abbott's formula was used to correct for control mortality greater than $15 \%$ [24].

Field experiments were analyzed using JMP 10 software [25]. Leptinotarsa decemlineata larval counts, percentage defoliation, and marketable yield were analyzed using ANOVA. Insect numbers were square root ( + 0.05 ) transformed prior to analysis. Defoliation data were arc sine, square root transformed prior to analysis. Mean comparisons were conducted using Fisher's LSD at the $P \leq 0.05$ level of significance. Untransformed data were reported in all tables.

\section{Results}

\subsection{Leaf Dip Bioassays}

Tolfenpyrad was highly toxic to L. decemlineata larvae and adults with corresponding LC $_{50}$ values of 13 and $164 \mathrm{ppm}$, respectively. The 95\% confidence intervals for the $\mathrm{LC}_{50}$ levels are $10.0-16.0 \mathrm{ppm}$ for the larvae and 101.0 - $266.0 \mathrm{ppm}$ for the adults. Thus, tolfenpyrad was approximately 12 times more toxic to larvae. Figure 1 shows the combined concentration-mortality response of $L$. decemlineata populations to tolfenpyrad in Painter, VA. The adult and larvae $\mathrm{r}^{2}$ values were 0.9663 and 0.9584 , respectively.

\subsection{Egg Mass Bioassays}

High field rate of tolfenpyrad resulted in a $0 \%$ hatch rate and the control of water had $100 \%$ of the egg masses hatch 5 days after treatment (DAT). It is important to note, of all the insecticide treated egg masses only a single egg hatched (Table 1).

\subsection{Field Trials}

In 2010, L. decemlineata pressure was moderate with an average of 70 larvae per 10 vines in the untreated control plots. There was a significant treatment effect on the abundance of $L$. decemlineata larvae (Table 2). In general, all tolfenpyrad treatments provided effective control of $L$. decemlineata. The first count on 17 May indicated significantly fewer small larvae in the tolfenpyrad treated plots $(\mathrm{F}=5.69 ; \mathrm{df}=5,15 ; P=0.0039)$. On 24 May, a significant treatment effect was observed on small ( $\mathrm{F}=6.39 ; \mathrm{df}=5,15 ; P=0.0023$ ) and large larvae ( $\mathrm{F}$ $=18.71 ; \mathrm{df}=5,15 ; P<0.0001)$ as well as defoliation $(\mathrm{F}=9.97 ; \mathrm{df}=5,15 ; P=0.0002)$ (Table 2). Plots with the $230 \mathrm{~g}$ ai/ha rate of tolfenpyrad and the tolfenpyrad mixed with $\beta$-cyfluthrin treatment yielded significantly more marketable potatoes $(\mathrm{F}=3.09$; $\mathrm{df}=5,15 ; P=0.0411)$.

Results from 2011 were similar to those in 2010, and all treatments of tolfenpyrad provided effective control (Table 3). There was a significant treatment effect for small ( $\mathrm{F}=6.06 ; \mathrm{df}=3,9 ; P=0.0152)$ and large larvae ( $\mathrm{F}$ $=6.08 ; \mathrm{df}=3,9 ; P=0.0153)$ on 26 May and on $2 \mathrm{Jun}(\mathrm{F}=31.05 ; \mathrm{df}=3,9 ; P<0.0001)(\mathrm{F}=9.90 ; \mathrm{df}=3,9 ; P=$ 


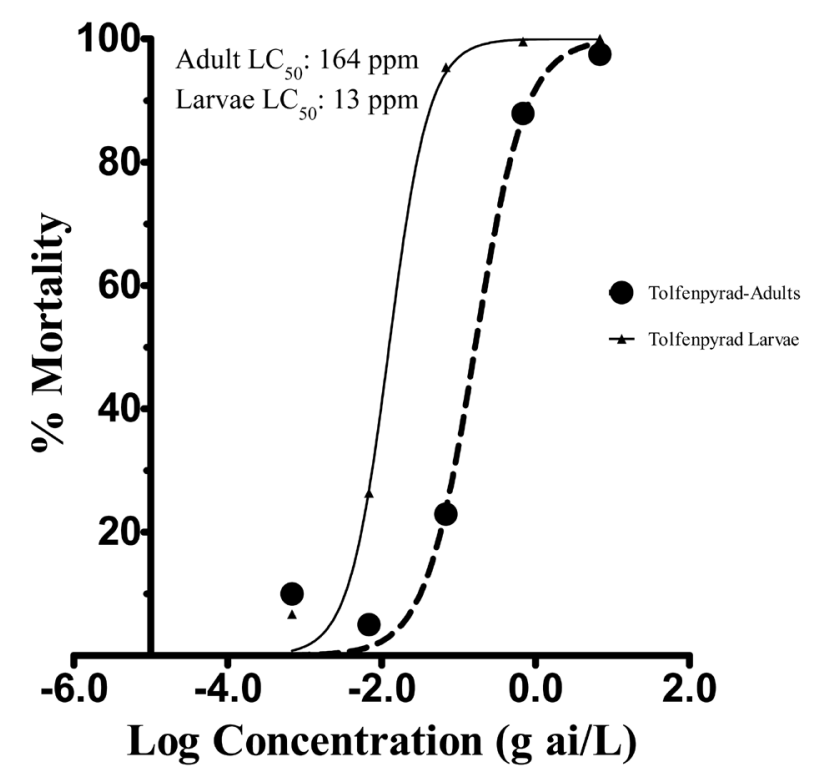

Figure 1. Baseline concentration-mortality response of $L$. decemlineata populations to tolfenpyrad. Plotted points are based on cumulative mortality of $L$. decemlineata adults and larvae for each concentration of tolfenpyrad from 2010 to 2012.

Table 2. Mean \pm SEM of $L$. decemlineata larvae, percent defoliation, and yield in potato plots treated with foliar insecticides. All treatments were sprayed on 11 and 18 May in Painter, VA, 2010.

\begin{tabular}{|c|c|c|c|c|c|c|c|}
\hline \multirow[b]{3}{*}{ Treatment } & \multirow[b]{3}{*}{ Rate (g ai/ha) $)^{z}$} & \multicolumn{4}{|c|}{ Mean no. $L$. decemlineata/10 stems } & \multirow[b]{3}{*}{ \% Defoliation } & \multirow[b]{3}{*}{ Yield $(\mathrm{kg} / \mathrm{m})$} \\
\hline & & \multicolumn{2}{|c|}{ 17-May (6 DAT 1) } & \multicolumn{2}{|c|}{ 24-May (6 DAT 2) } & & \\
\hline & & Small Larv ${ }^{y}$ & Large Larv ${ }^{x}$ & Small Larv & Large Larv & & \\
\hline NTC & & $60.0 \pm 16.5 \mathrm{a}$ & $12.0 \pm 8.7$ & $47.0 \pm 21.4 \mathrm{a}$ & $30.3 \pm 6.3 \mathrm{a}$ & $48.8 \pm 11.7 \mathrm{a}$ & $3.4 \pm 0.2 \mathrm{a}$ \\
\hline Tolfenpyrad & 153 & $10.8 \pm 5.6 \mathrm{bc}$ & $0.3 \pm 2.2$ & $3.5 \pm 1.2 \mathrm{~b}$ & $0.0 \pm 2.5 \mathrm{c}$ & $7.5 \pm 2.7 \mathrm{~b}$ & $4.2 \pm 0.2 \mathrm{bc}$ \\
\hline Tolfenpyrad & 186 & $16.3 \pm 6.2 \mathrm{bc}$ & $0.0 \pm 2.1$ & $0.0 \pm 4.3 \mathrm{~b}$ & $0.0 \pm 2.5 \mathrm{c}$ & $7.0 \pm 4.2 \mathrm{~b}$ & $4.3 \pm 0.3 \mathrm{bc}$ \\
\hline Tolfenpyrad & 230 & $12.5 \pm 5.1 \mathrm{bc}$ & $0.8 \pm 1.7$ & $2.8 \pm 5.5 b$ & $1.5 \pm 1.5 \mathrm{c}$ & $7.8 \pm 1.8 \mathrm{~b}$ & $4.4 \pm 0.4 \mathrm{bc}$ \\
\hline Tolfenpyrad $+\beta$-cyfluthrin & $153+14$ & $5.3 \pm 6.5 \mathrm{c}$ & $0.8 \pm 1.6$ & $0.0 \pm 4.3 \mathrm{~b}$ & $1.3 \pm 2.0 \mathrm{c}$ & $3.5 \pm 4.6 \mathrm{~b}$ & $4.7 \pm 0.3 \mathrm{c}$ \\
\hline$\beta$-cyfluthrin & 14 & $30.8 \pm 8.6 a b$ & $4.3 \pm 2.5$ & $6.0 \pm 6.6 b$ & $9.3 \pm 2.3 b$ & $15.5 \pm 2.1 \mathrm{~b}$ & $3.6 \pm 0.3 \mathrm{ab}$ \\
\hline \multicolumn{2}{|c|}{$P$-Value from ANOVA } & 0.0039 & ns & $<0.0023$ & $<0.0001$ & 0.0002 & 0.0411 \\
\hline
\end{tabular}

${ }^{\mathrm{z}}$ All treatments received $0.25 \%$ v:v non-ionic surfactant. ${ }^{y}$ Values followed by the same letter are not significantly different according to Fisher's LSD, $P=0.05 .{ }^{x}$ ns $=$ not significant.

0.0033), respectively; as well as a significant treatment effect on defoliation $(\mathrm{F}=23.01$; $\mathrm{df}=3,9 ; P=0.0001)$ (Table 3). There was no significant treatment effect on tuber yield.

The 2012 field season was similar to the previous two seasons; in general, all treatments of tolfenpyrad provided effective control of $L$. decemlineata larvae (Table 4). Plots treated with tolfenpyrad had a significant treatment effect for small $(\mathrm{F}=19.20 ; \mathrm{df}=3,15 ; P<0.0001)$ and large larvae $(\mathrm{F}=53.40 ; \mathrm{df}=3,15 ; P<0.0001)$ on 18 May. On 29 May, there was a significant treatment effect on small $(\mathrm{F}=5.11 ; \mathrm{df}=3,15 ; P=0.0124$ ) and large larvae (F $=46.28 ; \mathrm{df}=3,15 ; P<0.0001)$. There was also a significant treatment effect on defoliation $(\mathrm{F}=70.24 ; \mathrm{df}=3,15$; $P<0.0001)$ (Table 4). Unlike 2011, there was a significant treatment effect on yield $(\mathrm{F}=18.61 ; \mathrm{df}=3,15 ; P<$ $0.0001)$ and the tolfenpyrad treated plots produced significantly more marketable potatoes. 
Table 3. Mean \pm SEM of $L$. decemlineata larvae, percent defoliation, and yield in potatoes plots treated with foliar insecticides. All treatments were sprayed on 20 and 27 May in Painter, VA, 2011.

\begin{tabular}{|c|c|c|c|c|c|c|c|}
\hline \multirow[b]{3}{*}{ Treatment } & \multirow[b]{3}{*}{ Rate (g ai/ha) } & \multicolumn{4}{|c|}{ Mean no. L. decemlineata/10 stems } & \multirow[b]{3}{*}{ \% Defoliation } & \multirow[b]{3}{*}{ Yield $(\mathrm{kg} / \mathrm{m})^{y}$} \\
\hline & & \multicolumn{2}{|c|}{ 26-May (8 DAT 1) } & \multicolumn{2}{|c|}{ 2-Jun (8 DAT 2) } & & \\
\hline & & Small Larv ${ }^{2}$ & Large Larv & Small Larv & Large Larv & & \\
\hline NTC & & $27.0 \pm 8.5 \mathrm{a}$ & $44.0 \pm 12.2 \mathrm{a}$ & $14.0 \pm 3.1 \mathrm{a}$ & $17.0 \pm 4.7 \mathrm{a}$ & $23.75 \pm 4.4 \mathrm{a}$ & $2.0 \pm 0.8$ \\
\hline Tolfenpyrad & 153 & $2.0 \pm 3.4 b$ & $3.0 \pm 6.2 b$ & $0.0 \pm 1.0 \mathrm{~b}$ & $0.0 \pm 1.1 \mathrm{~b}$ & $1.25 \pm 2.2 \mathrm{~b}$ & $3.1 \pm 1.0$ \\
\hline Tolfenpyrad & 186 & $0.0 \pm 2.7 b$ & $13.0 \pm 8.1 b$ & $0.0 \pm 1.0 \mathrm{~b}$ & $0.0 \pm 1.1 \mathrm{~b}$ & $0.0 \pm 1.1 \mathrm{~b}$ & $2.8 \pm 0.4$ \\
\hline Tolfenpyrad & 230 & $0.0 \pm 2.7 b$ & $0.0 \pm 6.1 \mathrm{~b}$ & $0.0 \pm 1.0 \mathrm{~b}$ & $2.0 \pm 2.8 b$ & $0.0 \pm 1.1 \mathrm{~b}$ & $1.8 \pm 0.5$ \\
\hline \multicolumn{2}{|c|}{$P$-Value from ANOVA } & 0.0153 & 0.0152 & $<0.0001$ & 0.0033 & 0.0001 & ns \\
\hline
\end{tabular}

${ }^{\mathrm{z}}$ Values followed by the same letter are not significantly different according to Fisher's LSD, $p=0.05$. ${ }^{y}$ ns $=$ not significant.

Table 4. Mean \pm SEM of $L$. decemlineata larvae, percent defoliation, and yield in potatoes plots treated with foliar insecticides. All treatments were sprayed on 11 and 21 May in Painter, VA, 2012.

\begin{tabular}{|c|c|c|c|c|c|c|c|}
\hline \multirow[b]{3}{*}{ Treatment } & & \multicolumn{4}{|c|}{ Mean no. $L$. decemlineata/10 stems } & \multirow[b]{3}{*}{ \% Defoliation } & \multirow[b]{3}{*}{ Yield $(\mathrm{kg} / \mathrm{m})$} \\
\hline & & \multicolumn{2}{|c|}{ 18-May (7 DAT 1) } & \multicolumn{2}{|c|}{ 29-May (8 DAT 2) } & & \\
\hline & Rate (g ai/ha) ${ }^{z}$ & Small Larv ${ }^{y}$ & Large Larv & Small Larv & Large Larv & & \\
\hline NTC & & $127.0 \pm 17.4 \mathrm{a}$ & $35.5 \pm 5.5 \mathrm{a}$ & $19.8 \pm 5.7$ a & $25.5 \pm 4.2 \mathrm{a}$ & $73.33 \pm 6.2 \mathrm{a}$ & $3.8 \pm 0.2 \mathrm{a}$ \\
\hline Tolfenpyrad & 153 & $20.2 \pm 10.6 \mathrm{~b}$ & $1.2 \pm 2.0 \mathrm{~b}$ & $4.2 \pm 3.5 \mathrm{~b}$ & $1.3 \pm 1.5 \mathrm{~b}$ & $5.8 \pm 2.2 \mathrm{~b}$ & $4.8 \pm 0.1 b$ \\
\hline Tolfenpyrad & 186 & $8.7 \pm 5.3 b$ & $0.2 \pm 1.8 \mathrm{~b}$ & $0.8 \pm 2.4 \mathrm{~b}$ & $1.7 \pm 1.5 \mathrm{~b}$ & $6.7 \pm 2.0 \mathrm{~b}$ & $4.9 \pm 0.1 b$ \\
\hline Tolfenpyrad & 230 & $12.0 \pm 5.0 \mathrm{~b}$ & $0.2 \pm 1.7 \mathrm{~b}$ & $3.0 \pm 1.9 \mathrm{~b}$ & $1.0 \pm 1.3 \mathrm{~b}$ & $5.8 \pm 2.5 b$ & $5.3 \pm 0.1 b$ \\
\hline \multicolumn{2}{|c|}{$P$-Value from ANOVA } & $<0.0001$ & $<0.0001$ & 0.0124 & $<0.0001$ & 0.0001 & $<0.0001$ \\
\hline
\end{tabular}

${ }^{z}$ All treatments received $0.25 \%$ v:v non-ionic surfactant. ${ }^{y}$ Values followed by the same letter are not significantly different according to Fisher's LSD, $P=0.05$.

\section{Discussion}

Research has shown tolfenpyrad to be effective on a number of insect pests in a variety of crops. These include green peach aphids Myzus persicae (Sulzer) (Hemiptera: Aphididae) on broccoli Brassica oleracea L. potato leafhopper nymphs, Empoasca fabae (Harris) (Hemiptera: Cicadellidae) in potato western flower thrips, Frankliniella occidentalis (Pergande) (Thysanoptera: Thripidae), in lettuce Lectuca sativa var. longifloria, Lam. [26]-[29]. Our research showed that the pyrazole-5-carboxamide insecticide, tolfenpyrad, was highly toxic to $L$. decemlineata eggs, larvae, and adults. The larval stage of $L$. decemlineata is more susceptible to tolfenpyrad. This was not surprising as $L$. decemlineata larvae have been shown to be more susceptible than adults to many other insecticides including, azadirachtin [17] [30] [31], Bacillus thuringiensis subsp. tenebrionis [17] [32], and cyromazine [17] [33] [34]. In all three years, the first generation of $L$. decemlineata was successfully controlled by tolfenpyrad at the lowest rate tested, $153 \mathrm{~g}$ ai/ha. In the first field trial, the addition of the pyrethroid $\beta$-cyfluthrin at a rate of $14 \mathrm{~g}$ ai/ha to tolfenpyrad did not improve efficacy, therefore this treatment was not included in the other field experiments. This is consistent with other studies that found tolfenpyrad equally effective at controlling L. decemlineata as many of the currently used insecticides [35] [36].

Leptinotarsa decemlineata has demonstrated a high predilection for developing resistance to insecticides. Specifically, $L$. decemlineata has shown resistance to all or some of the compounds classified in the arsenical, organochlorine, carbamate, organophosphate, pyrethroid, and neonicotinoid classes of chemistry [10] [18]. Because potato growers in the United States rely heavily on neonicotinoids at planting for control of L. decemlineata and the concern for cross-resistance [18] [37], it is imperative that growers alternate insecticides with different modes of action [38]. However, potato growers have limited choices for effective non-neonicotinoid foliar insecticide treatments. We found that two foliar applications of tolfenpyrad at a rate of $153 \mathrm{~g} \cdot \mathrm{ai} / \mathrm{ha}$ or higher was 
sufficient to control the first generation of $L$. decemlineata on potatoes. The high level of field efficacy on all life stages of $L$. decemlineata and novel mode of action make tolfenpyradan ideal candidate for resistance management. However, because $L$. decemlineata has exhibited a variety of mechanisms that facilitate the development of pesticide resistance [18] [39]-[42], additional studies are needed to confirm the physiological impact of tolfenpyrad on $L$. decemlineata to evaluate the potential for cross-resistance. Nevertheless, potato-producing regions, where L decemlineata has shown resistance to neonicotinoids and other insecticides, could benefit from incorporating tolfenpyrad into pest management programs.

\section{Acknowledgements}

This study was conducted with the support of the Eastern Shore Agricultural Research and Extension Center's entomology summer crew and the farm crew. Funding for this study was provided by Nichino America Inc. We would also like to thank the commercial producers who provided access to their fields for insect collections.

\section{References}

[1] Capinera, J.L. (2001) Handbook of Vegetable Pests. Academic Press, New York.

[2] Alyokhin, A. (2009) Colorado Potato Beetle Management on Potatoes: Current Challenges and Future Prospects. Fruit, Vegetable and Cereal Science and Biotechnology, 1, 10-19.

[3] Hare, J.D. (1990) Ecology and Management of the Colorado Potato Beetle. Annual Review of Entomology, 35, 81-100. http://dx.doi.org/10.1146/annurev.en.35.010190.000501

[4] Hare, J.D. (1980) Impact of Defoliation by the Colorado Potato Beetle on Potato Yields. Journal of Economic Entomology, 73, 369-373. http://dx.doi.org/10.1093/jee/73.3.369

[5] Kuhar, T.P., Mori, K. and Dickens, J.C. (2006) Potential of a Synthetic Aggregation Pheromone for Integrated Pest Management of Colorado Potato Beetle. Agricultural and Forest Entomology, 8, 77-81. http://dx.doi.org/10.1111/j.1461-9555.2006.00286.x

[6] Kuhar, T.P., Doughty, H., Hitchner, E. and Cassell, M.E. (2008) Evaluation of Foliar Insecticides for the Control of Colorado Potato Beetle in Potatoes in Virginia, 2007. Arthropod Management Tests, 33, E8. http://dx.doi.org/10.1093/amt/33.1.E8

[7] Kuhar, T.P. and Doughty, H. (2009) Evaluation of Foliar Insecticides for the Control of Colorado Potato Beetle in Potatoes, 2008. Arthropod Management Tests, 34, E71.

[8] Ferro, D.N. (1993) Potential for Resistance to Bacillus thuringiensis: Colorado Potato Beetle (Coleoptera: Chrysomelidae) a Model System. American Entomologist, 39, 38-44. http://dx.doi.org/10.1093/ae/39.1.38

[9] Bishop, B.A. and Grafius, E.J. (1996) Insecticide Resistance in the Colorado Potato Beetle. In: Jolivet, P. and Hsiao, T.H., Eds., Chrysomelidae Biology, SBP Academic Publishing, Amsterdam.

[10] Alyokhin, A.V., Baker, M., Mota-Sanchez, D., Dively, G. and Grafius, E. (2008) Colorado Potato Beetle Resistance to Insecticides. American Journal of Potato Research, 85, 395-413. http://dx.doi.org/10.1007/s12230-008-9052-0

[11] Whalon, M.E. and Ferro, D.N. (1998) Bt-Potato Resistance Management. In: Mellon, M. and Rissler, J., Eds., Now or Never: Serious New Plans to Save a Natural Pest Control, UCS, Cambridge, 107-136.

[12] Huseth, A.S., Groves, R.L., Chapman, S.A., Alyokhin, A., Kuhar, T.P., Macrae, I.V., Szendrei, Z. and Nault, B.A. (2014) Managing Colorado Potato Beetle Insecticide Resistance: New Tools and Strategies for the Next Decade of Pest Control in Potato. Journal of Integrated Pest Management, 5, 1-8. http://dx.doi.org/10.1603/IPM14009

[13] Whalon M., Mota-Sanchez, D., Hollingworth, R. and Duynslager, L. (2015) Arthropod Pesticide Resistance Database. http://www.pesticideresistance.com/

[14] Grafius, E. (1997) Economic Impact of Insecticide Resistance in the Colorado Potato Beetle (Coleoptera: Chrysomelidae) on the Michigan Potato Industry. Journal of Economic Entomology, 90, 1144-1151. http://dx.doi.org/10.1093/jee/90.5.1144

[15] Huseth, A.S. and Groves, R.L. (2013) Effect of Insecticide Management History on Emergence Phenology and Neonicotinoid Resistance in Leptinotarsa decemlineata (Coleoptera: Chrysomelidae). Journal of Economic Entomology, 106, 2491-2505. http://dx.doi.org/10.1603/EC13277

[16] Chen, J., Alyokhin, A., Mota-Sanchez, D., Baker, M. and Whalon, M. (2014) Variation in Fitness among Geographically Isolated Colorado Potato Beetle (Coleoptera: Chrysomelidae) Populations. Annals of Entomological Society of America, 107, 128-135. http://dx.doi.org/10.1603/AN13018

[17] Kuhar, T.P., Kamminga, K., Philips, C., Wallingford, A. and Wimer, A. (2013) Chemical Control of Potato Pests. In: Giordanengo, P., Vincent, C. and Alyokhin, A., Eds., Insect Pests of Potato: Global Perspectives on Biology and 
Management, Elsevier, Waltham, MA, 375-397. http://dx.doi.org/10.1016/B978-0-12-386895-4.00013-2

[18] Mota-Sanchez, D., Hollingworth, R.M., Grafius, E.J. and Moyer, D.D. (2006) Resistance and Cross-Resistance to Neonicotinoid Insecticides and Spinosad in the Colorado Potato Beetle, Leptinotarsa decemlineata (Say) (Coleoptera: Chrysomelidae). Pest Management Science, 62, 30-37. http://dx.doi.org/10.1002/ps.1120

[19] Szendrei, Z., Grafius, E., Byrne, A. and Ziegler, A. (2012) Resistance to Neonicotinoid Insecticides in Field Populations of the Colorado Potato Beetle (Coleoptera: Chrysomelidae). Pest Management Science, 68, 941-946. http://dx.doi.org/10.1002/ps.3258

[20] Nonaka, N. (2003) Tolfenpyrad-A New Insecticide with Wide Spectrum and Unique Action. Agrochemicals Japan, 83, 17-19.

[21] Anonymous (2012) Tofenpyrad Insecticide: A New Broad-Spectrum Insecticide from Nichino America, Inc. Technical Bulletin, TOL-TIB-1201.

[22] USDA (2011) Agricultural Marketing Service. United States Standards for Grades of Potatoes.

[23] Motulsky, H.J. (2007) Prism 5 Statistics Guide. Graph Pad Software Inc., San Diego.

[24] Abbott, W.S. (1925) A Method of Computing the Effectiveness of an Insecticide. Journal of Economic Entomology, 18, 265-267. http://dx.doi.org/10.1093/jee/18.2.265a

[25] SAS (2013) JMP Version 10. SAS Institute, Cary.

[26] Natwick, E.T. (2012) Insecticide Efficacy against Thrips in Romaine Lettuce, Spring 2011. Arthropod Management Tests, 37, E26.

[27] Kuhar, T.P., Schultz, P., Doughty, H., Wimer, A., Wallingford, A., Andrews, H., Phillips, C., Cassell, M. and Jenrette, J. (2011) Evaluation of Foliar Insecticides for the Control of Green Peach Aphid in Broccoli in Virginia, 2010. Arthropod Management Tests, 36, E4.

[28] Kuhar, T.P., Schultz, P., Doughty, H., Wimer, A., Wallingford, A., Andrews, H., Phillips, C., Cassell, M. and Jenrette, J. (2011) Evaluation of Foliar Insecticides for the Control of Insects in Potatoes in Virginia, 2010. Arthropod Management Tests, 36, E64.

[29] Burrack, H. and Chapman, A. (2012) Tomato Spotted Wilt Virus Management in Tobacco with Unregistered Materials, 2011. Arthropod Management Tests, 37, F90.

[30] Trisyono, A. and Whalon, M.E. (1999) Toxicity of Neem Applied Alone and in Combinations with Bacillus thuringiensis to Colorado Potato Beetle (Coleoptera: Chrysomelidae). Journal of Economic Entomology, 92, 1281-1288. http://dx.doi.org/10.1093/jee/92.6.1281

[31] Kowalska, J. (2007) Azadirachtin as a Product for Control of Colorado Potato Beetles. Journal of Research and Applications in Agricultural Engineering, 52, 78-81.

[32] Ghidiu, G. and Zehnder, G.W. (1993) Timing of the Initial Spray Application of Bacillus thuringiensis for Control of the Colorado Potato Beetle (Coleoptera: Chrysomelidae) in Potatoes. Biological Control, 3, 348-352. http://dx.doi.org/10.1006/bcon.1993.1046

[33] Sirota, J.M. and Grafius, E. (1994) Effects of Cryomazine on Larval Survival, Pupation, and Adult Emergence of Colorado Potato Beetle (Coleoptera: Chrysomelidae). Journal of Economic Entomology, 87, 577-582. http://dx.doi.org/10.1093/jee/87.3.577

[34] Linduska, J.J., Ross, M., Mulford, K. and Baumann, D. (1996) Colorado Potato Beetle Control with Foliar Insecticide Sprays, 1995. Arthropod Management Tests, 21, E28.

[35] Byrne, A.M. and Szendrei, Z. (2012) Colorado Potato Beetle Control, 2011. Arthropod Management Tests, 37, E46

[36] Byrne, A.M. and Szendrei, Z. (2013) Colorado Potato Beetle Control, 2012. Arthropod Management Tests, 38 , E49.

[37] Alyokhin, A., Dively, G., Patterson, M., Mahoney, M., Castaldo, C., Rogers, D. and Wollam, J. (2007) Resistance and Cross-Resistance to Imidacloprid and Thiamethoxam in the Colorado Potato Beetle Leptinotarsa decemlineata. Pest Management Science, 63, 32-41. http://dx.doi.org/10.1002/ps.1305

[38] Alyokhin, A., Dively, G., Patterson, M., Mahoney, M., Castaldo, C., Rogers, D. and Wollam, J. (2007) Susceptibility of Imidacloprid-Resistant Colorado Potato Beetle to Non-Neonicotinoid Insecticides in the Laboratory and Field Trials. American Journal of Potato Research, 83, 485-494. http://dx.doi.org/10.1007/BF02883509

[39] Roush, R.T., Hoy, C.W., Ferro, D.N. and Tingey, W.M. (1990) Insecticide Resistance in the Colorado Potato Beetle (Coleoptera: Chrysomelidae): Influence of Crop Rotation and Insecticide Use. Journal of Economic Entomology, 83, 315-319. http://dx.doi.org/10.1093/jee/83.2.315

[40] Heim, D.C., Kennedy, G.G., Gould, F.L. and Van Duyn, J.W. (1992) Inheritance of Fenvalerate and Carbofuran Resistance in Colorado Potato Beetles, Leptinotarsa decemlineata (Say), from North Carolina. Pesticide Science, 34, 303311. http://dx.doi.org/10.1002/ps.2780340402 
[41] Miyo, T., Keil, C.B.O., Hough-Goldstein, J.A. and Oguma, Y. (1999) Inheritance of Resistance to Esfenvalerate in Colorado Potato Beetle (Coleoptera: Chrysomelidae) Populations. Journal of Economic Entomology, 93, 447-458.

[42] Hawthorne, D.J. (2003) Quantitative Trait Locus Mapping of Pyrethroid Resistance in Colorado Potato Beetle, Leptinotarsa decemlineata (Say) (Coleoptera: Chrysomelidae). Journal of Economic Entomology, 96, 1021-1030.

http://dx.doi.org/10.1093/jee/96.4.1021 